\title{
El bordado en oro de Archidona
}

El taller de Juan Antonio Lara está situado, tal y como él mismo apunta, "en la calle Don Carlos, frente a los Escolapios de Archidona donde estudió Blas Infante". Es una vivienda de arquitectura popular que adapta sus instalaciones a las necesidades del taller. Tras el zaguán, nos recibe la imagen de una virgen vestida, a escala humana, que preside el recibidor de la casa. En la segunda planta, una habitación luminosa con balcón a la calle del mismo nombre hace las veces de sala de bordado donde se instala el bastidor y el armario que guarda los hilos dorados y las pequeñas herramientas.

El origen del taller nace por iniciativa de Juan Antonio, que empieza bordando para su hermandad, y tras unos años en talleres de Málaga, que refuerza con cursos de bordados, monta el taller junto con su hermano, Antonio, y Manolo, un tercer bordador. Juan lleva veintiún años bordando y domina todas las técnicas productivas del taller, aunque, dentro del mismo, cada uno tiene sus propias funciones. Juan documenta e investiga técnicas de bordados de la zona, Antonio realiza los dibujos del diseño y Manolo se encarga del corte.

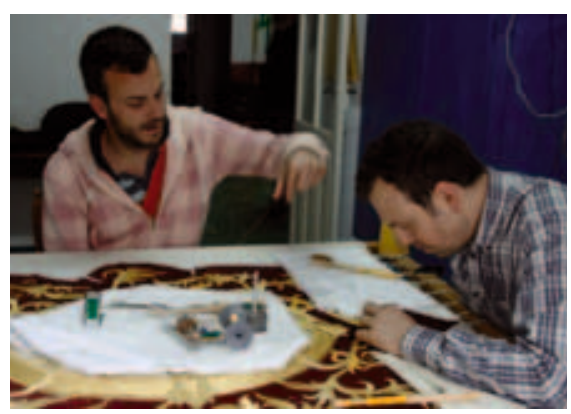

Juan A. y su hermano Antonio en el taller de la calle Don Carlos. Foto: Isabel Aguilar Majarón, IAPH

En el taller la materia prima para el bordado es el hilo de oro, que se obtiene enrollando una lámina de plata sobredorada sobre un hilo de seda. "Los hilos son los colores de la paleta del pintor". De este hilo liso se obtienen otras variedades como el hilo torzal que se logra torciendo sobre sí mismo varios cabos de hilos. Éste, a su vez, presenta otras variedades, dependiendo de los cabos utilizados. El hilo muestra es completamente liso y en su interior lleva otros hilos de seda; es uno de los más usados en el bordado en oro, pero hay que tener mucha maestría en su empleo, por la dificultad que presenta su acabado. El hilo jiraspe es una mezcla de hilo de oro con hilo de seda de distintos colores. El hilo granito es picoteado y su fin es crear este efecto sobre el tejido. El hilo de hojuela es una lámina de plata sobredorada, con el que se perfilan las pinturas centrales de los estandartes. El bordado entonces forma un cordón metálico que simula una pieza de orfebrería.

Tras ser aceptado un encargo, el diseño definitivo se traspasa al papel de seda y se despieza "nosotros tenemos que ir desguazando el dibujo". En algunos casos, los dibujos necesitan despiezarse en cada uno de sus elementos; por ejemplo, una rosa hay que despiezarla pétalo a pétalo. Es un proceso complicado, porque cada elemento debe coincidir después con el dibujo marcado. Este procedimiento se complejiza aún más si la cofradía presenta un escudo con elementos simbólicos (cosa muy habitual). En este caso, las piezas se montan en otro bastidor más pequeño para bordarse aisladamente. Posteriormente se recortan (se le quita la tela de muselina sobrante) y se colocan "como si se confeccionara un puzle". Se van pegando y perfilando. En cambio, en el bordado en cartón, las piezas de cartón (cartulina), ya recortadas, se pegan con pequeñas puntadas sobre la tela del bastidor y se bordan con el hilo de oro. La técnica del bordado en cartón es una de las técnicas de bordado en oro que más gusta en Archidona. El resto de elementos se borda sobre el tejido y los remates finales se perfilan con los acabados.

Fernández de Paz (1998: 387), en su análisis sobre los talleres cofradieros, relaciona los instrumentos (de sujeción y soporte, para medir y trazar, contención, ensamblaje y montaje) y las técnicas productivas con la materia prima empleada. La plasticidad de los hilos de metal dan como resultado la simplicidad de los instrumentos, de la misma manera que las técnicas productivas se definen por su escasa complejidad y por la manualidad en todos sus procesos productivos. El bordado en oro se realiza sobre una tela, generalmente terciopelo, con un forro en el reverso de trama densa (muselina morena). Para ello, la hebra del hilo de oro se pasa de lado a lado fijándola sobe el diseño con pequeñas puntadas de hilos. Esta hebra de seda hay que ir engrasándola con cera, para que no se endurezca y parta. El hilo de oro formará el dibujo en el anverso del textil y debe ir completamente recto este proceso es muy laborioso y hay que ejecutarlo con maestría tensando bien el bastidor. "...Dentro de bordado hay tantas puntadas como bordadores, cada bordador da la puntada según lo que le inspira esa pieza. Pero todo el trabajo tiene que ir enfocado a imitar a la Naturaleza" (Juan Antonio).

Las tipologías de puntadas y bordados más utilizadas en este taller son: de ladrillitos para dar textura de uniformidad, de ladrillito doble para dar mayor uniformidad aún, la puntada en flecha, que va buscando una dirección, la puntada de fresa que imita sus relieves y huecos con pequeños puntitos "uno, dos, tres, dos y uno" (Antonio).

El bordado en cartón (recortes en cartulina), que utiliza distintas texturas, el bordado de hojuela u hojilla es una de las técnicas de bordado más laboriosas, porque con una lámina de plata sobredorada de aproximada-

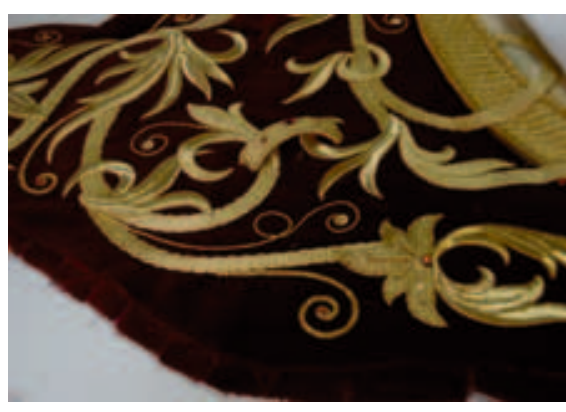

Bordado con incrustaciones en pedrería y motivo de puntada de ladrillitos. Foto: Isabel Aguilar Majarón, IAPH

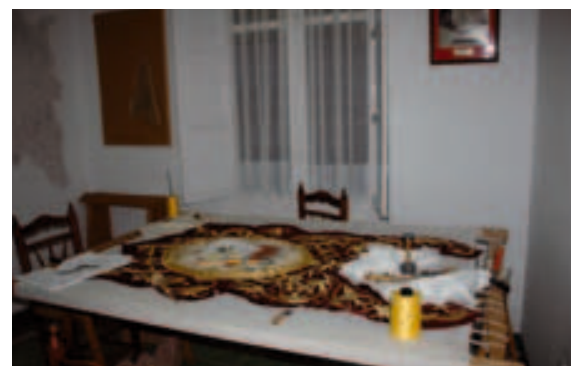

Taller con bastidor, hilos e instrumentos de bordado. Foto: Isabel Aguilar Majarón, IAPH

mente un milimetro de anchura se rellena toda la pieza, puntada a puntada, de manera uniforme. El acabado final es un cordón de oro de gran brillo y redondez.

Los bordados se enriquecen con lentejuelas y piedrecitas en colores de cristal engarzado, para captar la atención del cortejo en cada giro o movimiento.

La característica más señalada de este taller es que en él se reproducen diseños y técnicas de bordados cofradieros del pasado, tanto de Archidona como de otros pueblos de la comarca. Para ello buscan en los antiguos ajuares de las cofradias y en los viejos arcones de las iglesias: "Afortunadamente aqui no hubo mucho expolio durante la guerra asi los que trabajos se investigan y sirven de inspiración para los nuevos encargos recibidos."

En sus diseños, juegan con los relieves y las formas, lo que ellos denominan el "color" y la "textura". Los claros-oscuros se consiguen combinando figuras planas con las de relieve. Buscan crear distintas tonalidades realzando los contrastes contraponiendo figuras en distintas direcciones.

En estos talleres las fases productivas son poco diferenciadas, lo que da como resultado que el tiempo de aprendizaje sea mayor. Como consecuencia, estos centros son los que experimentan menos cambios a lo largo del tiempo. Se mantiene en lo que Fernández de Paz denomina la "paleotecnia" (1998: 395). Es decir, un oficio que, a diferencia de la mayoría, no introduce ningún procedimiento mecánico en sus fases productivas.

El discurso de este taller es recuperar los bordados de la zona, para preservar las variedades locales de los bordados de la Semana Santa "aqui gusta más el bordado en cartón, en Sevilla, por el contrario gusta más el picoteao". Sus encargos generalmente establecen de manera clara que ejecuten la obra con las técnicas de bordados "al gusto de Archidona".

En Archidona aún podemos documentar la presencia de representaciones teatrales en la Hermandad del Huerto. Sus bordados neobarrocos, casi inalterables durante siglos, reafirman el carácter festivo y teatral otrora prohibidos, cuyas supervivencias, casi inalterables en los talleres de bordados, gozan de buenas previsiones de futuro.

Isabel Aguilar Majarón, antropóloga 